\title{
The pharmacokinetics of transdermal flunixin in lactating dairy goats
}

\author{
Enoch B. de S. Meira Jr., Emily E. Wiloch, $\odot$ Emma Nixon, $\odot$ James L. Yeatts, Farha Ferdous Sheela, \\ Geof W. Smith, $(1)$ and Ronald E. Baynes* () \\ Department of Population Health and Pathobiology and the Food Animal Residue Avoidance and Depletion Program (FARAD), \\ North Carolina State University, Raleigh 27607
}

\begin{abstract}
Flunixin is a nonsteroidal anti-inflammatory drug approved for use in cattle to manage pyrexia associated with bovine respiratory disease, mastitis, and endotoxemia. In the United States, no nonsteroidal anti-inflammatory drugs are approved for use in goats, but analgesics are needed for management of painful conditions to improve animal welfare. The objective of this study was to evaluate the pharmacokinetics of transdermal flunixin in dairy goats to determine a milk withdrawal interval (WDI) to avoid violative residue contamination in the food supply. Six adult lactating dairy goats received $3.3 \mathrm{mg} / \mathrm{kg}$ of transdermal flunixin before milk, interstitial fluid (ISF), and blood samples were collected at various time points for $360 \mathrm{~h}$. The samples were analyzed using tandem mass spectrometry to detect flunixin as well as the flunixin marker metabolite, 5-hydroxyflunixin followed by a pharmacokinetic WDI calculation using the US Food and Drug Administration tolerance limit method to propose safe residue levels in goat milk. The mean flunixin apparent plasma half-life was $21.63 \mathrm{~h}$. The apparent milk half-life for 5-hydroxyflunixin was $17.52 \mathrm{~h}$. Our findings provide a milk WDI of $60 \mathrm{~h}$ using the US Food and Drug Administration tolerance of $0.002 \mu \mathrm{g} / \mathrm{mL}$ (established for bovine milk) and a more conservative WDI of $96 \mathrm{~h}$ using a limit of quantification of $0.001 \mu \mathrm{g} / \mathrm{mL}$ following the extralabel use of transdermal flunixin in dairy goats.
\end{abstract}

Key words: transdermal flunixin, goat, pharmacokinetics, drug residue, milk

\section{INTRODUCTION}

Flunixin is a nonsteroidal anti-inflammatory drug (NSAID) approved for transdermal use in cattle to manage pyrexia associated with respiratory disease, and

Received March 15, 2021.

Accepted August 27, 2021.

*Corresponding author: Ronald_Baynes@ncsu.edu pain associated with foot rot in beef cattle and replacement dairy heifers under 20 mo of age. A new transdermal formulation is approved for use in beef cattle but not lactating dairy cattle (US FDA, 2017). Mechanistically, NSAIDs block the cyclooxygenase pathway, thus inhibiting the production of prostaglandins associated with inflammation and pain (Lees, 2017). In cattle, the transdermal formulation is absorbed rapidly, has a longer half-life than the intravenous formulation, and has been successful in managing musculoskeletal pain (Kleinhenz, et al., 2016, 2019). In addition, the transdermal formulation is easier for owners to administer on-farm as compared with the parent formulation which must be given intravenously in cattle.

In the United States, no NSAIDs are approved for use in goats by the Food and Drug Administration (FDA), however flunixin is commonly administered in an extralabel manner to dairy goats to provide analgesia for mastitis, lameness, and other painful conditions (Plummer and Schleining, 2013). For withdrawal time determination, flunixin depletion in milk is measured by monitoring the metabolite 5-hydroxyflunixin (5-OH-FLU; US FDA, 2020). The United States tolerance for 5 -OH-FLU in cow milk is $0.002 \mu \mathrm{g} / \mathrm{mL}$. However, because flunixin is not approved by the FDA for use in dairy goats, there is no tolerance for its marker residue (5-OH-FLU) in goat milk (ECFR, 2020), and the veterinarian and producer should follow all requirements of the Animal and Medicinal Drug Use Clarification Act of 1994 (AMDUCA, 1994). Extralabel drug use of flunixin is legal in the United States when it is prescribed by a licensed veterinarian, a valid veterinarian-client-patient relationship is established, and all requirements of the AMDUCA are followed (Monti, 2020). Extralabel use of drugs directly affects the withdrawal time necessary to avoid potentially harmful residues in food products. In these cases, extended withdrawal intervals (WDI) scientifically based on pharmacokinetic drug studies are necessary to estimate an appropriate interval and ensure food safety (FARAD, 2020).

Pharmacokinetic studies of transdermal flunixin have been reported for dairy cows (Gorden et al., 2019; 
Kleinhenz et al., 2016) and meat goats (Reppert et al., 2019), but no studies have been completed in dairy goats. The first objective of this study was to determine the kinetics disposition of flunixin and its metabolite, 5-OH-FLU, in plasma, interstitial fluid (ISF), and milk following the administration of a single dose of $3.3 \mathrm{mg} /$ $\mathrm{kg}$ of transdermal flunixin $(50 \mathrm{mg} / \mathrm{mL})$ in lactating dairy goats. The second objective was to use the data generated from these studies for the estimation of milk WDI following extralabel use of this drug formulation.

\section{MATERIALS AND METHODS}

\section{Animals and Housing}

The study was approved by the North Carolina State University Institutional Animal Care and Use Committee (IACUC \#17-132-A). Six adult female dairy French Alpine goats between the ages of 2 to $6 \mathrm{yr}$ old with no history of flunixin administration in a previous 30-d period were enrolled in this study. This study was limited to 6 dairy goats in order the fit the enrollment criteria of being in mid lactation, healthy, no previous history of exposure to drugs or mastitis, and obtained from a single farm within short geographical distance as these animals were rented and had to be returned to the owner at the end of the study. The selected goats were in mid lactation, ranging from 120 to 160 DIM, and had a daily milk production ranging from 0.5 to 2 L. All goats were determined to be healthy based on physical examination. The goats were weighed upon arrival and their weights ranged from 40.5 to $80.4 \mathrm{~kg}$. The goats were sourced from a local commercial dairy and housed at the North Carolina State University College of Veterinary Medicine. The animals were individually housed in metabolism cages to prevent cross contamination of transdermal flunixin. The goats were fed coastal Bermuda grass hay and a grain diet that either met or exceeded the National Research Council requirements for maintenance of goats at their respective production status (NRC, 1981). The goats were hand milked twice a day by trained personnel throughout the study.

Twenty-four hours before dosing the goats, a 16-gauge intravenous catheter (MILA International, Inc.) was placed into the right jugular vein using sterile technique. A RUF-3-12 reinforced in vivo ultrafiltration sampling probe (MF-7028, BASi Systems) was then placed subcutaneously in the dorsal thoracic vertebrae region above the epaxial muscles on the left side, for collection of ISF. A preweighed vacuum collection tube with no additives (BD Vacutainer, Terumo) was attached to the ultrafiltration probe system and weighed after collec- tion. The ISF tube length and sample weights were recorded so that a lag time could be calculated.

\section{Dosing and Sample Collection}

All the goats had blank milk, ISF, and plasma samples collected before dosing. Each goat was administered a single dose transdermal flunixin (Banamine Transdermal, Merck Animal Health) at $3.3 \mathrm{mg} / \mathrm{kg}$ in a line down the right side of their back from the cervicothoracic junction to the mid-lumbar region using a disposable, single-use syringe. A separate individual who did not collect any samples dosed the goats to prevent cross contamination. The medication was administered down the right side of the back to prevent the drug from reaching the ISF probe that was placed on the left side of the goat in the dorsal thoracic vertebrae region. Care was taken throughout the study to not touch the area of dosing.

Each goat had a specific person collecting their samples to avoid cross contamination and avoid missing any collection time points. Blood samples were collected at 0 (before treatment), $0.16,0.33,0.5,0.75,1,1.5,2$, 4,8 , and $12 \mathrm{~h}$ after treatment. The ISF samples were collected at 0 (before treatment), 4, 8, and $12 \mathrm{~h}$ after treatment. Milk was collected at $12 \mathrm{~h}$ after treatment and milk volumes were recorded. Sample collection time points were extrapolated from previous studies in dairy cattle (Kleinhenz et al., 2016) and meat goats (Reppert et al., 2019).

Following the initial 12-h collection period, all samples were then collected every $12 \mathrm{~h}$ for $15 \mathrm{~d}(360 \mathrm{~h})$. After each milking, $1 \mathrm{~mL}$ of milk was transferred into 3 separate cryovials, and then placed in a $-80^{\circ} \mathrm{C}$ freezer until analysis. Three milliliters of blood was taken directly from the jugular catheter and placed to the side to ensure that blood samples were not contaminated with heparinized flush. Two milliliters of blood was then collected from the catheter and placed into sodium heparin tubes (BD Vacutainer, Terumo, Loeven, Belgium). Plasma was separated by centrifugation at $1,500 \times g$ for $10 \mathrm{~min}$ at $4^{\circ} \mathrm{C}$, harvested into cryovials, and then placed in $-80^{\circ} \mathrm{C}$ until analyzed.

A lag time for ISF was calculated using the following equation: (lag time $=$ tube volume/flow rate). The lag time was calculated to determine how long it took the sample to travel through the ISF tubing (Nixon et al., 2020). Tube volume was confirmed in the laboratory and the flow rate was estimated by weighing the sample collected to determine the volume collected and then dividing the collected volume by the time period the sample was collected. The average lag time specific for 
ISF material used in this study for the dairy goat ISF collection was approximately $0.58 \mathrm{~h}$. The tubes containing the ISF samples were weighed, and pre and postcollection weights were recorded. The ISF was equally divided between 2 cryovials. All cryovials were stored in $-80^{\circ} \mathrm{C}$ until analyzed. One limitation of the ISF probes and its associated lag time is that the drug or metabolite concentration value reported at the time point the tube is removed is an average value of the interval in which the sample was collected rather than a value in the ISF at the time collected.

\section{Sample Measurements}

Flunixin and 5-OH-FLU concentrations were determined by ultra-performance liquid chromatography with tandem mass spectrometric detection (UPLC-MS/MS). Individual stock solutions of flunixin and 5-OH-FLU were dissolved in methanol then mixed to make a $500 \mu \mathrm{g} / \mathrm{mL}$ mixed stock solution. The mixed stock solution was diluted with 1:1 acetonitrile: water to prepare the spiking solutions.

The goat plasma calibration standards were prepared by spiking $200 \mu \mathrm{L}$ of blank plasma with $10 \mu \mathrm{L}$ of the appropriate concentrations to establish a linear calibration range for both compounds in plasma of $0.0005-0.1$ $\mu \mathrm{g} / \mathrm{mL}$. Four hundred microliters $(400 \mu \mathrm{L})$ of $4 \%$ phosphoric acid was added to the plasma calibration standards and samples then vortexed briefly. A Waters Oasis PRIME $\mu$ Elution plate (Waters Corp.) was preconditioned with $500 \mu \mathrm{L}$ of methanol followed by $500 \mu \mathrm{L}$ of water. The $600 \mu \mathrm{L}$ of pretreated plasma was loaded into the $\mu$ Elution well, eluted slowly, then washed with $600 \mu \mathrm{L}$ of 95:5 water:methanol. A new clean sample collection plate was placed into the vacuum manifold (Waters Corp.). The analytes were eluted with $50 \mu \mathrm{L}$ of 70:30 acetonitrile:methanol then diluted by adding $50 \mu \mathrm{L}$ of water directly to each sample collection plate well. A cap mat was pressed onto the top of the sample collection plate and gently swirled before placing it directly into the UPLC/MS/MS for analysis.

Goat milk calibration standards were prepared by spiking $600 \mu \mathrm{L}$ of blank milk with $100 \mu \mathrm{L}$ of the appropriate flunixin and 5-OH-FLU mixed standard concentration to establish a linear calibration range for both compounds in milk of 0.0005 to $0.05 \mu \mathrm{g} / \mathrm{mL}$ One hundred microliters of blank 1:1 acetonitrile:water was also added to each $600-\mu \mathrm{L}$ milk sample. The milk calibration standards and samples were then treated with $1,800 \mu \mathrm{L}$ of acetonitrile containing $0.1 \%$ formic acid and vortex mixed thoroughly. The samples were centrifuged at $1,500 \times g$ for $10 \mathrm{~min}$ at $4^{\circ} \mathrm{C}$. Two milliliters of the supernatant was loaded onto an Agilent Captiva
EMR-lipid 3-mL (300-mg) cartridge (Agilent Technologies). The eluate was evaporated to dryness under air at $55^{\circ} \mathrm{C}$, reconstituted in $300 \mu \mathrm{L}$ of $1: 1$ acetonitrile: water, and filtered with a Whatman PVDF $0.2 \mu \mathrm{m}$ Mini-UniPrep syringeless filter device (GE Healthcare UK Ltd.).

The spiking solutions used to spike goat ISF were dissolved in methanol. Goat ISF calibration standards were prepared by spiking $30 \mu \mathrm{L}$ of blank ISF with 50 $\mu \mathrm{L}$ of the appropriate concentration in methanol to establish a linear calibration range for both compounds in ISF of $0.001 \mu \mathrm{g} / \mathrm{mL}$ to $0.05 \mu \mathrm{g} / \mathrm{mL}$. Fifty microliters of methanol was added to $30 \mu \mathrm{L}$ of each ISF sample and vortexed briefly. The methanol diluted calibration standards and samples were filtered through 13-mm syringe filters, with $0.2-\mu \mathrm{m}$ polytetrafluoroethylene membrane (VWR International), directly into Waters total recovery vials (Waters Corp.) for analysis. An external matrix matched calibration plot with $1 / \mathrm{x}$ weighting (TargetLynx Software, Masslynx V4.1 SCN914, Waters Corp.) was used to determine the unknown concentrations in all matrices.

The UPLC-MS/MS system consisted of a Waters Acquity UPLC Sample Manager-FTN, Waters Acquity UPLC I-Class Binary Solvent Manager, and Waters Xevo TQD (Waters Corp.). The column was a Waters Acquity UPLC BEH phenyl $(2.1 \times 100 \mathrm{~mm}, 1.7-\mu \mathrm{m}$ particles) plus Vanguard precolumn $(2.1 \times 5 \mathrm{~mm}, 1.7$ $\mu \mathrm{m})$. The column and sample temperatures were $35^{\circ} \mathrm{C}$ and $20^{\circ} \mathrm{C}$, respectively. Mobile phase solvent A1 was $0.1 \%$ formic acid in water, and solvent B1 was $0.1 \%$ formic acid in acetonitrile. The wash solvent was 1:1:1:1 water:acetonitrile:methanol:isopropyl alcohol. The purge solvent was 90:10 water:acetonitrile. The preinjection and postinjection needle wash times were 0 and $10 \mathrm{~s}$, respectively. A gradient was used for the separation. The flow rate was $0.4 \mathrm{~mL} / \mathrm{min}$. The initial conditions for the gradient was 70:30 A1:B1 held for $1.00 \mathrm{~min}$. From 1.00 to $2.50 \mathrm{~min} \mathrm{~A} 1 \mathrm{~B} 1$ changed to 10:90 A1:B1 linearly (Curve 6), then held until 3.50 min. Finally, at 3.51 min the gradient was back to the initial conditions (70:30 A1:B1) and held until $5.00 \mathrm{~min}$. Total run time was $5.00 \mathrm{~min}$. The injection volume was $5.0 \mu \mathrm{L}$. A smaller injection volume of $0.3 \mu \mathrm{L}$ was used for repeating some plasma samples that were above the calibration range.

The Xevo TQD settings were as follows: The ionization mode was ES+ (electrospray ionization positive mode). The capillary $(\mathrm{kV})$ and cone $(\mathrm{V})$ voltages were 0.45 and 50 respectively. The source desolvation temperature was $550^{\circ} \mathrm{C}$. The desolvation $(\mathrm{L} / \mathrm{h})$ and cone $(\mathrm{L} / \mathrm{h})$ source gas flows were 1,000 and 50 , respectively. For MS file settings, the flunixin parent $(m / z)$ and 
daughters $(m / z)$ were 297.04 (parent), 263.97 (daughter 1 ), and 279.04 (daughter 2). The 5-OH-FLU $(\mathrm{m} / z)$ and daughters $(\mathrm{m} / z)$ were 312.97 (parent), 280.04 (daughter 1), and 295.06 (daughter 2). Dwell times(s) were 0.04 for flunixin and 0.120 for 5 -OH-FLU. The cone (V) voltages were 50 for flunixin and 56 for 5-OH-FLU. The collision $(\mathrm{V})$ voltages for flunixin daughters 1 and 2 were 33 and 22 , respectively. The collision (V) voltages for 5-OH-FLU daughters 1 and 2 were 36 and 24, respectively. The quantification trace for flunixin was $297.04>279.04$. The quantification trace for 5-OHFLU was $312.97>295.06$.

The limit of quantification (LOQ) for flunixin in milk was $0.0005 \mu \mathrm{g} / \mathrm{mL}$. The LOQ for 5 -OH-FLU in milk was $0.001 \mu \mathrm{g} / \mathrm{mL}$. The LOQ for both flunixin and 5 -OH-FLU in plasma was $0.001 \mu \mathrm{g} / \mathrm{mL}$. The control milk from each goat was used to obtain the best matrix matched calibration plot for each individual goat. Each milk sample was analyzed in triplicate. The limit of detection (LOD) was $0.0005 \mu \mathrm{g} / \mathrm{mL}$ for both compounds in milk and plasma except for flunixin in milk which was not determined. The LOD and LOQ were determined by analyzing 5 replicates of the same spiked concentration in milk. The lowest concentration that gave an accuracy between 85 and $115 \%$ with a relative standard deviation (RSD) $\leq 15 \%$ was defined as the LOQ. The LOD was defined as the lowest concentration detected below the LOQ that did not satisfy these accuracy and RSD criteria. The linear calibration range for both compounds in milk was 0.0005 to $0.050 \mu \mathrm{g} /$ $\mathrm{mL}$. The linear calibration range for both compounds in plasma was 0.005 to $0.1 \mu \mathrm{g} / \mathrm{mL}$ using an injection volume of $5.0 \mu \mathrm{L}$, and 0.001 to $0.5 \mu \mathrm{g} / \mathrm{mL}$ using an injection volume of $0.3 \mu \mathrm{L}$.

Due to the limited amount of blank goat ISF available, a 4-point calibration plot with each calibration standard analyzed in triplicate was used in estimating flunixin and 5-OH-FLU in goat ISF. The linear calibration range for both compounds in ISF was 0.001 to 0.05 $\mu \mathrm{g} / \mathrm{mL}$. The matrix matched calibration plots for all matrices had a coefficient of determination, $\mathrm{R}^{2}>0.99$.

Quality control standards were prepared in the same manner as the calibration standards by spiking the matrix with the appropriate concentration. For example, plasma was spiked to $0.5 \mu \mathrm{g} / \mathrm{mL}$ in 5 samples for a daily run and similarly milk was spiked to $0.01 \mu \mathrm{g} /$ $\mathrm{mL}$ for a daily run and for both matrices the RSD and accuracy were $<20 \%$ and 91 to $103.2 \%$, respectively.

For flunixin in goat milk, precision ranged from 5.8 to $13.6 \%$ and accuracy_ranged from 93.9 to $98.2 \%$ and for 5-OH-FLU in goat milk, precision ranged from 5.8 to $7.2 \%$ and accuracy ranged from 94.4 to $122.3 \%$. For flunixin in goat plasma, precision ranged from 3.6 to $20.2 \%$, and accuracy ranged from 93.2 to $101.3 \%$. For
5-OH-FLU in goat plasma, precision ranged from 2.2 to $16.6 \%$. and accuracy ranged from 96.8 to $104.1 \%$. For flunixin in goat ISF, the precision ranged from 3.8 to $13.6 \%$ and accuracy ranged from 89.7 to $110.8 \%$.

\section{Pharmacokinetic Analysis}

A noncompartmental analysis of drug concentration versus time profiles was performed with available software (Phoenix Win-Nonlin 8.0, Certara Inc.). The area under the concentration-time curve from time zero to infinity $(\mathbf{A U C 0} \rightarrow \infty ; \mathrm{h} \times \mu \mathrm{g} / \mathrm{mL})$ was calculated by the linear $\log$ trapezoid method. The terminal slope was used to determine apparent half-life $(\mathbf{T} \mathbf{1} / \mathbf{2} ; \mathrm{h})$. Peak plasma concentration $(\mathbf{C m a x} ; \mu \mathrm{g} / \mathrm{mL})$ and time at which maximum concentration occurs (Tmax; h) were taken directly from the data for each goat. The apparent clearance and volume of distribution per fraction absorbed are not reported due to limited usefulness for extravascularly administered drugs with unknown and low bioavailability. For milk, the Tmax rates were calculated due to the accumulation of milk over time between milkings. This is the midpoint of the collection interval associated with the maximum excretion rate. The total amount recovered in milk $(\mu \mathrm{g})$ were also reported, and a normalization by body weight was performed to examine the cause of variability between goats. Due to the accumulation of milk over time between milkings, the midpoint of each collection interval was determined and used to calculate an excretion rate for each interval. Excretion rate (amount eliminated per unit of time $)=($ concentration $\times$ volume $) /($ end ing time - starting time). Pharmacokinetic analysis of milk was performed on the average concentration value of the 3 replicates.

\section{Data Analysis for WDI Determination}

The WDI was calculated for 5-OH-FLU in goat milk following the FDA tolerance limit method (US FDA, 2006, 2018) but using R codes developed by our group. The LOQ and the assumed tolerance was chosen as 0.001 and $0.002 \mu \mathrm{g} / \mathrm{mL}$, respectively. The observed values that fell below the LOQ were removed before WDI calculation. In accordance with the FDA tolerance limit method was used to estimate the withdrawal period, we used a $99 \%$ tolerance limit with a $95 \%$ confidence to determine the withdrawal period. A tolerance limit can be either one-sided or 2-sided, which states that a certain percentage of observations lies below the upper limit or lies within the upper limit-lower limit interval. Following the FDA guidelines, a one-sided tolerance limit was used to estimate the WDI. 
The WDI is estimated based on the assumption that the mean of the log of concentration of residue for each animal is linearly related to time. We fit a linear regression model for each animal by ordinary least squares method. By partitioning the residual sum of squares into pure error sum of squares and lack of fit, the F-test is used for the final determination of the points to be included in the regression for each animal. For each animal, only the points that lie on or around the linear curve are included for further calculations. According to FDA guidelines, the exclusion of time points is done to satisfy the linearity and homoscedasticity assumptions. Following this suggestion, the time points 24, 60, and $72 \mathrm{~h}$ were used for goat 1 ; the time points 12,36 , and $48 \mathrm{~h}$ were used for goat 2 ; no time points were used for goat 3 ; the time points 12,60 , and $72 \mathrm{~h}$ were used for goat 4 ; the time points 24,36 , and $48 \mathrm{~h}$ were used for goat 5; and the time points $24,36,48$, and $60 \mathrm{~h}$ were used for goat 6 in the subsequent calculation of WDI.

In accordance with FDA guidance (US FDA, 2006, 2018) for calculating milk withdrawal times, the WDI calculations included a bulk tank factor $(\mathrm{m}=10$ animals) and used an assumed tolerance for 5-OH-FLU based on dairy cattle milk $(0.002 \mu \mathrm{g} / \mathrm{mL})$ or our assay LOQ $(0.001 \mu \mathrm{g} / \mathrm{mL})$. These values were multiplied by 3 as the $99 \%$ tolerance limit should be below 3 times the permitted residue concentration. The basis for this correction is that the FDA assumes that no more than one-third of the milk in a bulk tank will come from treated animals. A WDI was also calculated for another FDA guidance scenario when the entire herd was treated, and milk in the bulk tank was from all the treated animals and the 3 times permitted concentration correction was not used in the computation. FDA will not allow that correction and therefore this was not included in another computation scenario described above and only the permitted concentrated, which is our LOQ $(0.001 \mu \mathrm{g} / \mathrm{mL})$, was used in the computation for this other scenario.

\section{RESULTS}

No adverse effects were observed in the goats after administration of transdermal flunixin as assessed by daily physical examination and observation of drug administration site. There also appeared to be no negative effects on milk production following administration of the drug.

\section{Plasma}

Mean plasma flunixin and 5-OH-FLU concentrations throughout the study following $3.3 \mathrm{mg} / \mathrm{kg}$ transdermal

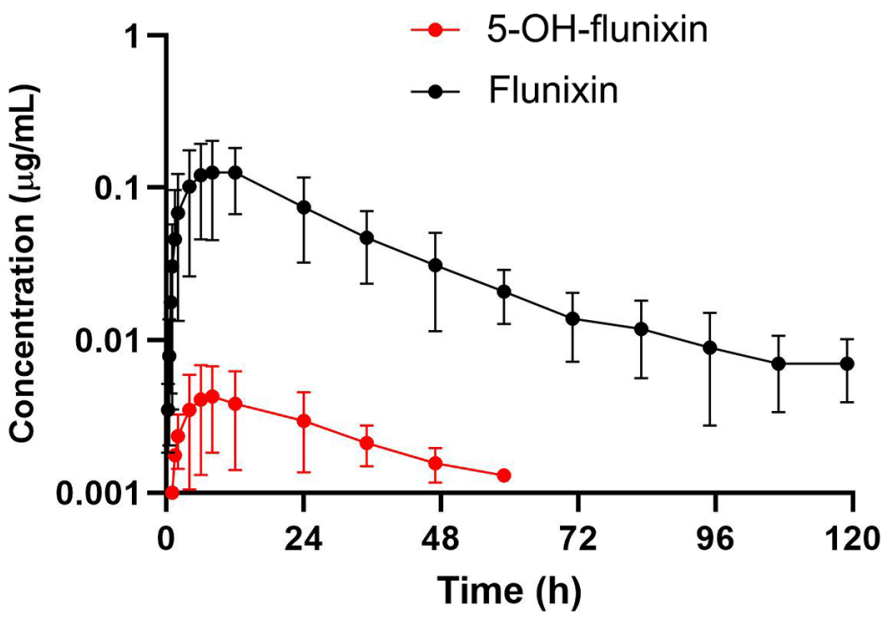

Figure 1. Flunixin and 5-hydroxyflunixin (5-OH-FLU) concentration (log scale axis) versus time profile in plasma from 6 goats following a single dose of transdermal flunixin $(3.3 \mathrm{mg} / \mathrm{kg})$. Data are presented as arithmetic mean $\pm \mathrm{SD}$. The dose of transdermal flunixin was administered at $0 \mathrm{~h}$.

flunixin are shown in Figure 1. Flunixin pharmacokinetic variables for each goat are presented in Table 1. The 5-OH-FLU pharmacokinetic variables for each goat are presented in Table 2. The pharmacokinetics of transdermal flunixin was characterized by moderately long Tmax (geometric mean $=10.48 \mathrm{~h}$ ), and a long apparent terminal half-life (geometric mean $=21.63$ h). The apparent half-life of 5-OH-FLU was also long (geometric mean $=17.79 \mathrm{~h})$. The geometric mean time to maximum plasma concentration (Tmax) for 5-OHFLU was $11.38 \mathrm{~h}$, which is longer than that of parent flunixin.

\section{Milk}

Following topical administration, flunixin was not present above the LOQ in the milk of all goats through $72 \mathrm{~h}$, therefore no pharmacokinetic parameters for milk flunixin could be reported. At $72 \mathrm{~h}$, all goats had 5-OHFLU concentrations that were below the assumed tolerance of $2 \mu \mathrm{g} / \mathrm{mL}$ (based on the FDA milk tolerance for cattle). Although below the assumed tolerance, 4 goats produced milk with concentrations above the LOQ $(0.001 \mu \mathrm{g} / \mathrm{mL})$, one goat produced milk that had detectable levels of 5-OH-FLU that were below LOQ but above the LOD $(0.005 \mu \mathrm{g} / \mathrm{mL})$, and one goat produced milk with no detectable 5-OH-FLU. Mean milk flunixin and 5-OH-FLU concentrations over time following a 3.3 $\mathrm{mg} / \mathrm{kg}$ dose of transdermal flunixin are shown in Figure 2. Individual goat pharmacokinetic variables of 5-OHFLU in milk are shown in Table 3. The drug mass was determined from the product of the concentration of 
Table 1. Noncompartmental plasma pharmacokinetic parameters of flunixin in plasma based on noncompartmental pharmacokinetic analysis following single administration of transdermal flunixin to dairy goats $(3.3 \mathrm{mg} / \mathrm{kg})^{1}$

\begin{tabular}{|c|c|c|c|c|c|c|c|}
\hline Goat & $\begin{array}{c}\mathrm{T} 1 / 2 \\
(\mathrm{~h})\end{array}$ & $\underset{(\mathrm{T})}{\operatorname{Tmax}}$ & $\begin{array}{c}\text { Cmax } \\
(\mu \mathrm{g} / \mathrm{mL})\end{array}$ & $\begin{array}{c}\text { AUCinf } \\
(\mathrm{h} \times \mu \mathrm{g} / \mathrm{mL})\end{array}$ & $\begin{array}{c}\text { AUClast } \\
(\mathrm{h} \times \mu \mathrm{g} / \mathrm{mL})\end{array}$ & $\begin{array}{c}\text { AUCextrap } \\
(\%)\end{array}$ & $\begin{array}{c}\text { MRT } \\
(\mathrm{h})\end{array}$ \\
\hline 1 & 21.15 & 6.00 & 0.17 & 5.19 & 5.06 & 2.53 & 32.24 \\
\hline 4 & 22.89 & 12.00 & 0.13 & 4.43 & 4.10 & 7.53 & 40.83 \\
\hline 5 & 30.32 & 24.00 & 0.10 & 5.71 & 5.24 & 8.20 & 50.42 \\
\hline 6 & 17.12 & 8.00 & 0.27 & 7.51 & 7.31 & 2.67 & 27.07 \\
\hline
\end{tabular}

${ }^{1} \mathrm{~T} 1 / 2=$ apparent half-life of drug; Tmax = time to maximum concentration; Cmax = maximum plasma concentration; AUCinf $=$ area under the concentration-time curve of total exposure of drug to the body; AUClast = area under the concentration-time curve from time zero to time of the last measurable concentration; AUCextrap = percentage of the area under the concentration-time curve extrapolated from the last observed time point; MRT $=$ mean residence time.

drug in milk and the milk volume from each goat. The geometric mean amount of total drug recovered from goats given a single dose of transdermal flunixin (3.3 $\mathrm{mg} / \mathrm{kg}$ ) was $28.87 \mu \mathrm{g}$. This was equivalent to $0.16 \mu \mathrm{g}$ of 5-OH-FLU recovered per mg of flunixin drug administered or $0.53 \mu \mathrm{g}$ recovered per $\mathrm{kg}$ of body weight. The geometric mean half-life of 5-OH-FLU in the milk was $17.52 \mathrm{~h}$. The Tmax rate, or the midpoint of the collection interval associated with the maximum observed excretion rate, had a geometric mean value of $10.82 \mathrm{~h}$. There was very limited amounts of parent flunixin detected in the milk. Only 2 goats had sufficient data to generate milk flunixin pharmacokinetic parameters and some goats also had increasing or plateaued concentrations. Therefore, there was not enough data above the LOQ to generate milk flunixin pharmacokinetic parameters and the data on flunixin concentrations in the milk is not reported. The 5-OH-FLU metabolite was the predominant compound detectible in milk following administration and average milk 5-OH-FLU concentrations were higher than average plasma 5-OH-FLU concentrations as depicted in Figures 1 and 2. The average
5-OH-FLU Cmax in milk was $0.007 \mu \mathrm{g} / \mathrm{mL}$ and the average 5-OH-FLU Cmax in plasma was $0.003 \mu \mathrm{g} / \mathrm{mL}$.

The WDI for 5-OH-FLU in dairy goat milk was estimated to be $57 \mathrm{~h}$ when the LOQ was set to $0.001 \mu \mathrm{g} /$ $\mathrm{mL}$ and the assumed tolerance was set to $0.002 \mu \mathrm{g} /$ $\mathrm{mL}$ (Figure 3a) When the LOQ was set to $0.001 \mu \mathrm{g} /$ $\mathrm{mL}$ and the assumed tolerance was set to $0.001 \mu \mathrm{g} /$ $\mathrm{mL}$, the WDI became $70 \mathrm{~h}$ (not presented) or $72 \mathrm{~h}$ for practical purposes according to US FDA guidance. When the latter was calculated without the 3 times permitted concentration correction, the WDI was $97 \mathrm{~h}$ (Figure 3b) or $96 \mathrm{~h}$ for practical purposes according to US FDA guidance when milk from entire treated herd contributed to the only milk in the bulk milk tank.

\section{ISF}

Figure 4 depicts the flunixin concentration vs time profile in ISF. Flunixin was detected in the ISF of all 6 goats until $72 \mathrm{~h}$. Levels of 5-OH-FLU were below the LOD in all ISF samples. Due to increasing or plateaued concentrations of flunixin in the ISF, no pharmacoki-

Table 2. Noncompartmental plasma pharmacokinetic (PK) parameters of 5-hydroxyflunixin in plasma based on noncompartmental PK analysis following single administration of transdermal flunixin to dairy goats $(3.3 \mathrm{mg} / \mathrm{kg})^{1}$

\begin{tabular}{|c|c|c|c|c|c|c|c|}
\hline Goat & $\begin{array}{c}\mathrm{T} 1 / 2 \\
(\mathrm{~h})\end{array}$ & $\underset{(\mathrm{h})}{\operatorname{Tmax}}$ & $\underset{(\mu \mathrm{g} / \mathrm{mL})}{\mathrm{Cmax}}$ & $\underset{(\mathrm{h} \times \mu \mathrm{g} / \mathrm{mL})}{\text { AUCinf }}$ & $\begin{array}{c}\text { AUClast } \\
(\mathrm{h} \times \mu \mathrm{g} / \mathrm{mL})\end{array}$ & $\begin{array}{c}\text { AUCextrap } \\
(\%)\end{array}$ & $\begin{array}{c}\mathrm{MRT} \\
(\mathrm{h})\end{array}$ \\
\hline 1 & 17.07 & 6.00 & 0.008 & 0.28 & 0.25 & 11.41 & 28.71 \\
\hline 2 & & 12.00 & 0.003 & & 0.04 & & \\
\hline 4 & 17.69 & 6.00 & 0.005 & 0.15 & 0.12 & 18.80 & 28.82 \\
\hline 5 & & 35.00 & 0.002 & & 0.08 & & \\
\hline 6 & 18.63 & 12.00 & 0.005 & 0.17 & 0.12 & 29.68 & 30.04 \\
\hline
\end{tabular}

${ }^{1}$ Missing values indicate insufficient data to calculate PK parameters for that animal. T1/2 = half-life of drug; Tmax = time to maximum concentration; Cmax = maximum plasma concentration; AUCinf = area under the concentration-time curve of total exposure of drug to the body; AUClast = area under the concentration-time curve from time zero to time of the last measurable concentration; AUCextrap = percentage of the area under the concentration-time curve extrapolated from the last observed time point; MRT $=$ mean residence time. 


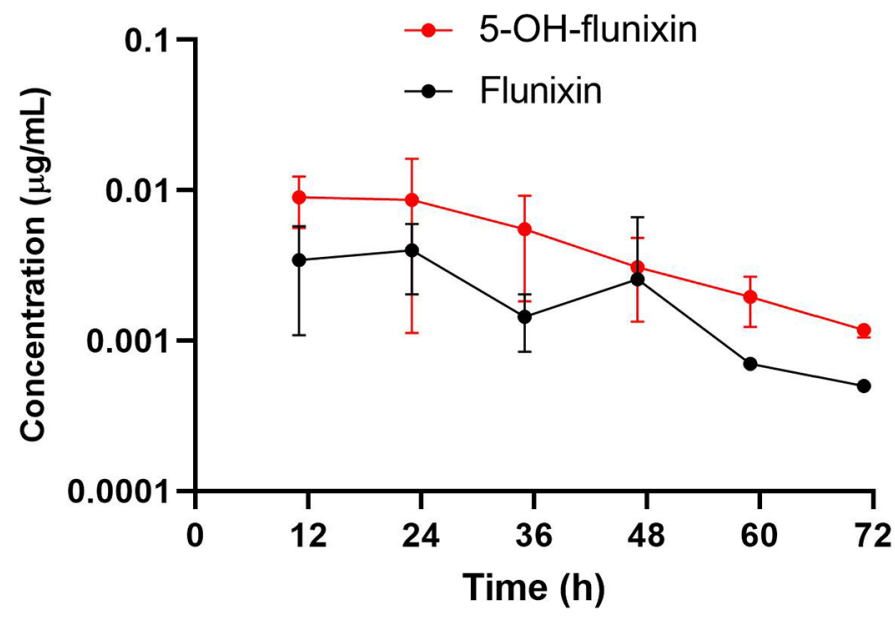

Figure 2. Flunixin and 5-hydroxyflunixin (5-OH-FLU) concentration (log scale axis) versus time profile in milk from 6 goats following a single dose of transdermal flunixin $(3.3 \mathrm{mg} / \mathrm{kg})$. Data are presented as arithmetic mean $\pm \mathrm{SD}$. The dose of transdermal flunixin was administered at $0 \mathrm{~h}$.

netic parameters were generated. There was no terminal phase present to calculate a half-life. However, flunixin ISF concentrations were approximately 10 times that in plasma and more than 100 times that in milk.

\section{DISCUSSION}

Our study is the first to report on the pharmacokinetic parameters of transdermal flunixin in healthy lactating dairy goats. This information allowed us to estimate a safe milk WDI for dairy goats who received $3.3 \mathrm{mg} / \mathrm{kg}$ of transdermal flunixin. Transdermal flunixin is the only NSAID currently approved for use in cattle in the United States and is approved for the control of pyrexia associated with bovine respiratory disease and the control of pain associated with foot rot in steers, beef heifers, beef cows, beef bulls (US FDA, 2017).

The transdermal formulation could be easier and less stressful to apply, making it an appealing option for goat producers and veterinarians. To use the drug safely in lactating goats, it is critical to establish an appropriate milk WDI. The use of flunixin as an anti-inflammatory drug in goats and its pharmacokinetic parameters has been investigated for different routes of administration; including oral, intramuscular (IM), and intravenous (IV) (Königsson et al., 2003), subcutaneous (SC) in dairy goats (Smith et al., 2020), and transdermal in meat goats (Reppert et al., 2019). In a model of induced lameness in cattle, transdermal flunixin was able to provide some degree of analgesia (Kleinhenz et al., 2019). However, in studies with both castration and dehorning in calves, transdermal flunixin was not able to demonstrate any significant effect on pain relief (Kleinhenz et al., 2017, 2018). However, in goats, transdermal flunixin improved fluidity of movement and decreased head pressing following castration indicating a mitigation of pain behavior (Graves et al., 2020). Transdermal flunixin has been shown to have a significant anti-inflammatory effect in cattle and significantly reduced prostaglandin E2 concentrations in a model of acute inflammation (Thiry et al., 2017). Evidence has been reported regarding efficacy of flunixin injectable formulation based on its ability to inhibit prostaglandin synthesis when administered through routes other than the intravenous route in goats (Königsson et al., 2003). Recently, the use a transdermal flunixin formulation in meat goats was shown not to meet the targeted plasma concentrations expected to achieve clinical efficacy due to low bioavailability, however, it did cause a reduction in prostaglandin E2 levels by $50 \%$ for a prolonged

Table 3. Pharmacokinetic (PK) parameters of 5-hydroxyflunixin in milk based on noncompartmental pharmacokinetic analysis following single administration of transdermal flunixin to dairy goats $(3.3 \mathrm{mg} / \mathrm{kg})^{1}$

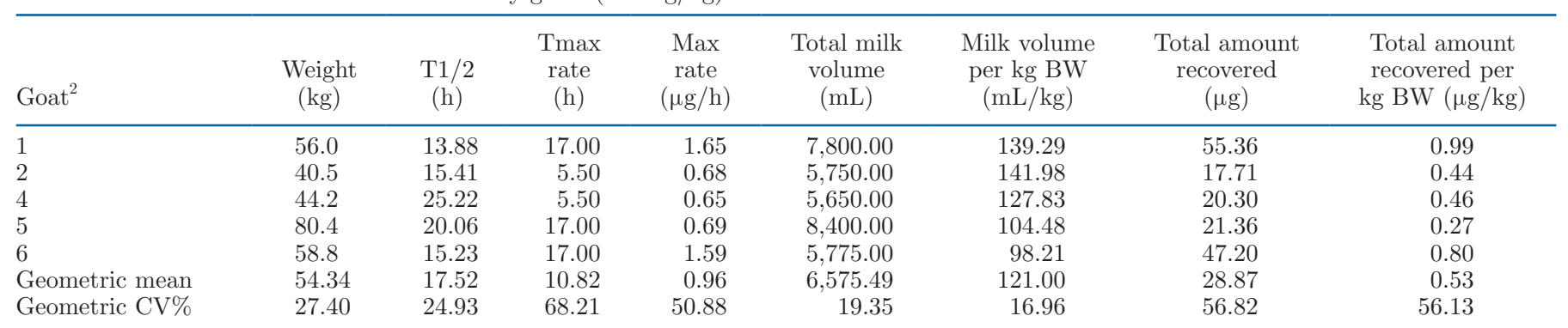

${ }^{1} \mathrm{~T} 1 / 2=$ half-life of drug; Tmax rate $=$ midpoint of the collection interval associated with the maximum observed excretion rate; max rate $=$ the maximum observed excretion rate; total milk volume = total volume milked per goat; milk volume per $\mathrm{kg}$ BW = total volume milked per $\mathrm{kg}$ of goat BW; total amount recovered = total drug recovered from milk; total amount recovered per $\mathrm{kg}$ BW = total amount of drug recovered per $\mathrm{kg}$ of BW per goat.

${ }^{2}$ Goat 3 did not have enough data points for PK analysis of 5-hydroxyflunixin in milk, and therefore it is not included here. 
A

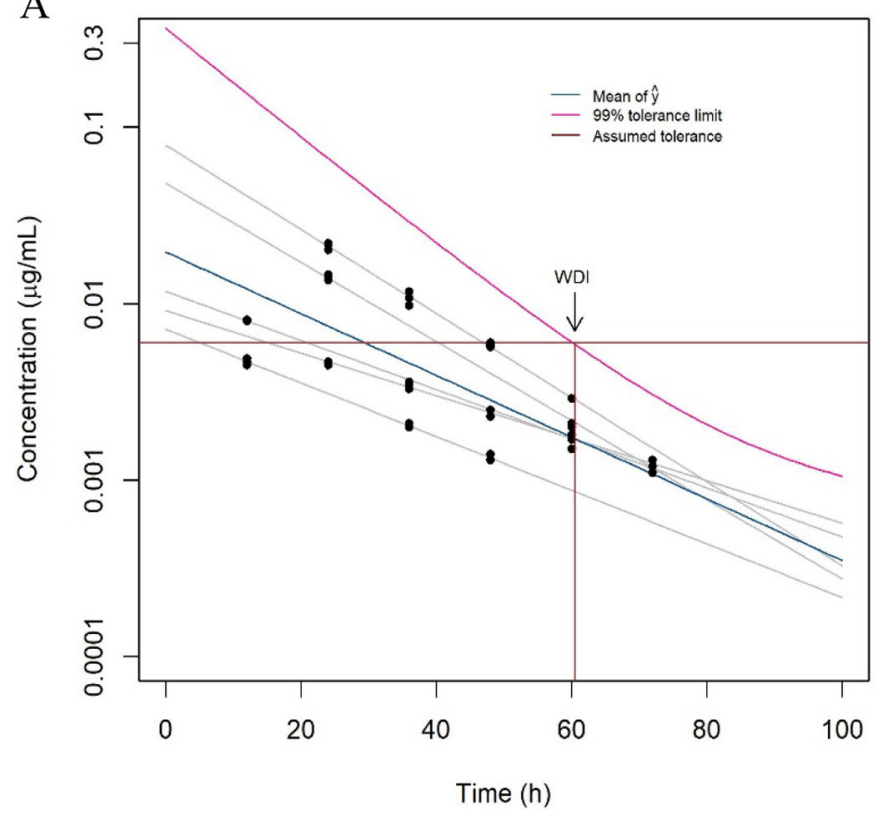

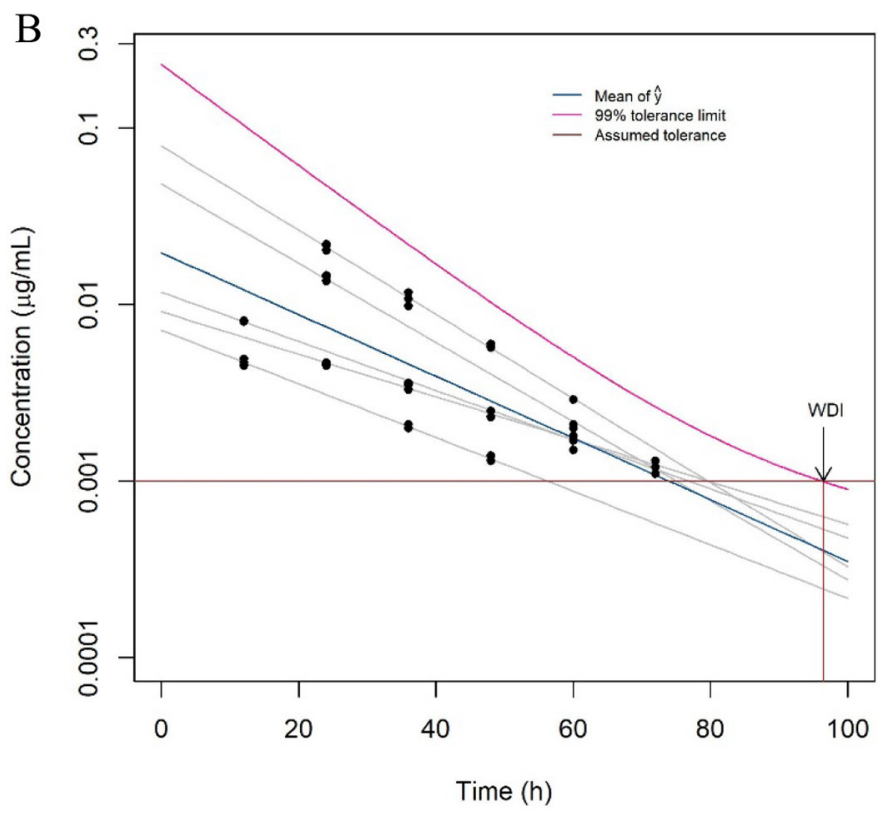

Figure 3. The fitted regression model, along with $99 \%$ tolerance limit, with 95\% confidence, for 5-hydroxyflunixin (5-OH-FLU) concentration (log scale axis) in goat milk (A) using a tolerance of $0.002 \mu \mathrm{g} / \mathrm{mL}$ (assumed tolerance) with the $\times 3$ correction, which shows a withdrawal interval (WDI) of $57 \mathrm{~h}$ or $60 \mathrm{~h}$ for practical purposes, and (B) using a limit of quantification $(0.001 \mu \mathrm{g} / \mathrm{mL})$ without the $\times 3 \mathrm{correction}$ factor, which shows a WDI of $97 \mathrm{~h}$ or $96 \mathrm{~h}$ for practical purposes.

period of time (Reppert et al., 2019). Further research is needed to evaluate the overall analgesic efficacy of flunixin when administered intravenously or topically.

After transdermal administration of $3.3 \mathrm{mg} / \mathrm{kg}$ in dairy goats, flunixin reached peak plasma concentra-

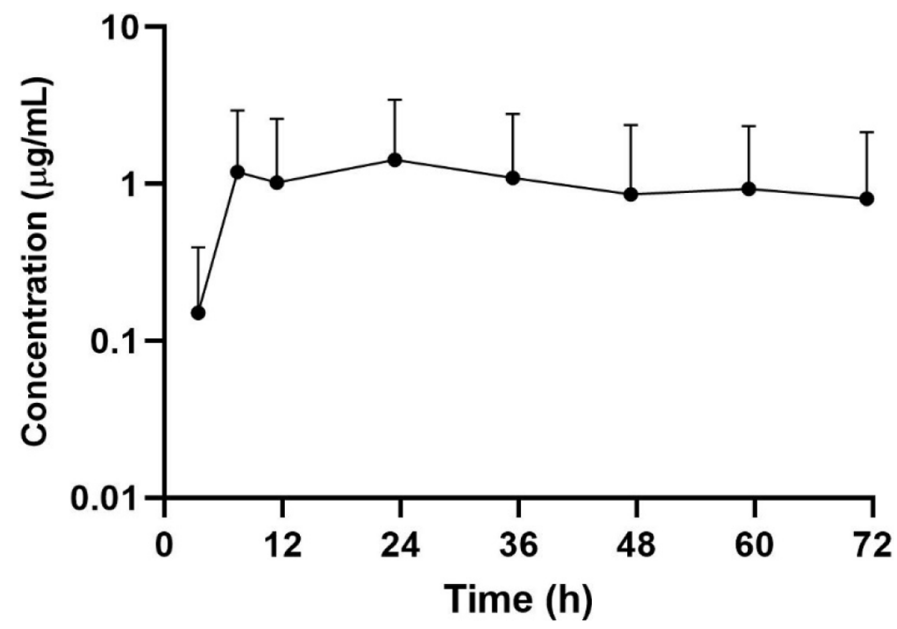

Figure 4. Flunixin concentration (log scale axis) versus time profile in interstitial fluid (ISF) from 6 goats following a single dose of transdermal flunixin $(3.3 \mathrm{mg} / \mathrm{kg})$. Data are presented as arithmetic mean \pm SD. Negative values for the lower SD could not be plotted on the semi-logarithmic scale. The ISF data were plotted to account for a sample collection lag time of $0.58 \mathrm{~h}$. tions (Tmax) in approximately $10.48 \mathrm{~h}$, which is very similar to the Tmax observed in meat goats of $11.41 \mathrm{~h}$ (Reppert et al., 2019). Dairy goats experienced a mean half-life of flunixin of $21.63 \mathrm{~h}$, which is much longer than that previously reported in dairy cattle of 6.42 $\mathrm{h}$ for transdermal administration (Kleinhenz et al., 2016) and $5.39 \mathrm{~h}$ following SC administration (Kissell et al., 2012). However, the dairy goats in our study had a shorter mean half-life than that of meat goats, which was $43.12 \mathrm{~h}$ (Reppert et al., 2019). This suggests that transdermal flunixin elimination in dairy goats is slower than that in dairy cattle, which is surprising because based on allometric scaling, smaller animals generally have faster metabolism (Toutain et al., 2010). Differences across species and production class could be due to differences in the skin anatomy, age, or differences in milk production due to genetics. This data also suggests that the transdermal flunixin elimination in dairy goats in our study is faster than that in meat goats, which could be due to the increased metabolism and energy it takes to produce milk in lactating animals. Higher flunixin plasma clearance after SC and IV administrations in lactating goats was reported when compared with nonlactating goats (Smith et al., 2020). The mean plasma Cmax in dairy goats from this study was $0.13 \mu \mathrm{g} / \mathrm{mL}$ as compared with $0.134 \mu \mathrm{g} / \mathrm{mL}$ in meat goats (Reppert et al., 2019) and $1.17 \mu \mathrm{g} / \mathrm{mL}$ in 
dairy cows (Kleinhenz et al., 2016). This shows that the drug reaches much higher plasma concentrations in dairy cows than it does in dairy goats, but meat goats and dairy goats have a very similar Cmax following transdermal flunixin application.

There was considerable variability observed in the total amount of 5-OH-FLU excreted in the goat milk. Because these goats were not from a homogeneous population, their genetics, and therefore metabolism and milk clearance, could be expected to vary considerably. The transdermal application of drugs can lead to increased pharmacokinetic variability, and differences in milk excretion volumes between animals can result in variable metabolite concentrations in the milk. In dairy cows, the Cmax of 5-OH-flunxin in milk was $0.061 \mu \mathrm{g} /$ $\mathrm{mL}$, and the Tmax was $8.0 \mathrm{~h}$ (Gorden et al., 2019). The Cmax of 5-OH-FLU in the milk of our dairy goats was $0.007 \mu \mathrm{g} / \mathrm{mL}$. The mean milk half-life of 5 -OH-FLU in dairy goats was $17.96 \mathrm{~h}$, which is shorter than the mean half-life of $22.62 \mathrm{~h}$ in dairy cows (Gorden et al., 2019). Because of the variability described above, these may not be significant differences in milk clearance across species for this metabolite.

It should be noted that in our transdermal study that the parent drug, flunixin, was not present above the LOQ in the milk of all goats through $72 \mathrm{~h}$, therefore no pharmacokinetic parameters for milk flunixin could be reported. Five out of the 6 goats in the study had the metabolite 5-OH-FLU residues in their milk above the LOQ up to $72 \mathrm{~h}$. Interestingly, 5-OH-FLU concentrations in milk were higher than in plasma (2.3 times difference) suggesting transport (active or passive) of the metabolite from plasma compartment to the milk compartment. Therefore, plasma levels may not be a reliable indicator of when milk is cleared of the metabolite, albeit their apparent half-lives are similar.

Following FDA guidelines described earlier, we used a one-sided tolerance limit procedure to estimate the WDI. This method is known to account for the degree of variation in the population and the sample size of the study. The WDI for 5-OH-FLU in the milk of lactating dairy goats treated with $3.3 \mathrm{mg} / \mathrm{kg}$ of transdermal flunixin was $57 \mathrm{~h}$ (Figure 3a) when the assumed tolerance used was $0.002 \mu \mathrm{g} / \mathrm{mL}$ and $70 \mathrm{~h}$ when the assumed tolerance used for the method was $0.001 \mu \mathrm{g} / \mathrm{mL}$. Because the FDA guidelines indicate that a fraction of a milking interval should not be used for a withdrawal time, we suggest a $60 \mathrm{~h}$ WDI for flunixin at a tolerance of $0.002 \mu \mathrm{g} / \mathrm{mL}$ and a $72-\mathrm{h}$ WDI when the assumed tolerance is $0.001 \mu \mathrm{g} / \mathrm{mL}$. When the latter computation was performed without the 3 times permitted concentration correction $(3 \times 0.001 \mu \mathrm{g} / \mathrm{mL})$ the WDI was $97 \mathrm{~h}$ (Figure 3b) or $96 \mathrm{~h}$ for practical purposes. The latter is allowed by FDA guidance when all of the milk in the milk tank came from all treated animals. These WDI estimates for the above scenarios are not approved withdrawal times from the FDA, but is a reliable estimate based on the data collected in this study.

Although the FDA tolerance level for 5-OH-FLU in cow milk is $0.002 \mu \mathrm{g} / \mathrm{mL}$, there is no regulatory tolerance for 5-OH-FLU in goat milk, nor is there an approved regulatory assay method. However, our calculations used an analytical method LOQ of our assay, which was $0.001 \mu \mathrm{g} / \mathrm{mL}$. This WDI calculation can change if different doses are used, a more sensitive assay is used (e.g., LOQ $<0.001 \mu \mathrm{g} / \mathrm{mL}$ ), or physiological status of animals changes. Using a different route of flunixin administration, formulation, and methodology, Smith et al. (2020) reported a milk WDI estimate of 36 to $60 \mathrm{~h}$ in dairy cattle. It is important to remember that transdermal flunixin is not approved for use in dairy goats according to the FDA. Furthermore, there are no regulatory assays approved for goats testing to the tolerance that is codified in cow milk.

In this study, we found very low concentrations of flunixin in the milk and higher concentrations of the metabolite 5-OH-FLU, which is expected. However, it has been shown that administration of the injectable formulation of flunixin to cows with clinical mastitis resulted in higher flunixin milk concentrations and a substantially longer period to deplete 5-OH-FLU from milk (Kissell et al., 2012). Therefore, it is quite possible that practitioners should consider employing the more conservative milk WDI of $96 \mathrm{~h}$ (Figure 3B) when treating sick goats that might have slower clearance than the healthy animals used in this project.

This study demonstrated higher flunixin concentrations in the ISF than in the plasma of dairy goats. Transdermal application appeared to generate plateaued concentrations of flunixin over $72 \mathrm{~h}$, which was unusual for ISF concentrations, which typically decline with time via other routes of administration (Nixon et al., 2020) albeit slower than in the plasma compartment. The analysis did not extend beyond $72 \mathrm{~h}$, therefore no terminal phase was observed and a half-life in ISF was not estimated. The data from this aspect of the study suggest that potential therapeutic concentrations could be delivered via this compartment, however this sustained flunixin concentration was not observed in either the plasma or milk samples over this time period. This ISF data suggest there is a depot source for flunixin, which can be metabolized to 5-OH-FLU and be eliminated in the milk and it also suggest that similar plateau concentrations may be associated with 
target tissues following this route of administration. This may require a tissue depletion study which was beyond the scope of this study.

In conclusion, one of the strengths of this study was that we identified the flunixin metabolite, 5-OH-FLU, as the more suitable marker residue in goat milk and this was the case with dairy cattle given flunixin. We were able to use FDA guidance to estimate a WDI of $96 \mathrm{~h}$ after goats were given a single dose of $3.3 \mathrm{mg} /$ $\mathrm{kg}$ of transdermal flunixin. Goats in this study were restrained to prevent self- or interanimal licking of the drug to allow for a more reliable pharmacokinetic evaluation. This behavioral effect on drug bioavailability and efficacy has been reported for transdermal products (Toutain et al., 2012). Several weaknesses should also be recognized; for example, in a commercial dairy setting, goats would typically be comingled and would not be isolated as described in this study. We also observed variability in the total amount of 5-OH-FLU excreted in the goat milk, which could be attributed to several biological factors already described, albeit the study was conducted in a controlled environment. It should also be noted that these goats were healthy and the metabolism of flunixin could differ greatly in a sick animal and our estimates provided here may not be applicable to unhealthy goats. Finally, the study was limited by the lack of a regulatory approved tolerance for goat milk and limited to our analytical chemistry laboratory LOQ for goat milk which limits the recommended WDI to our developed assay.

\section{ACKNOWLEDGMENTS}

The authors thank Celebrity Dairy (Siler City, NC) for loaning the goats used in this study. This research was supported by the USDA National Institute of Food and Agriculture (grants no. 2019-41480-30292 and 2020-41480-32520; Kansas City, MO) that fund the Food Animal Residue Avoidance and Depletion Program (FARAD). The authors have not stated any conflicts of interest.

\section{REFERENCES}

AMDUCA. 1994. Animal Medicinal Drug Use Clarification Act of 1994. Public Law 103-396. Oct. 22, 1994. Congr. Rec. 140.

ECFR (Electronic Code of Federal Regulations). 2020. Tolerances for residues of new animal drugs in food. Accessed Dec. 9, 2020. https://www.ecfr.gov/cgi-bin/retrieveECFR?gp=\&SID= $1 \mathrm{a} 4 \mathrm{a} 124 \mathrm{e} 2 \mathrm{c} 861 \mathrm{de} 1 \mathrm{dd} 3 \mathrm{c} 8 \mathrm{~d} 1567$ eaedbd\&mc $=$ true $\& \mathrm{n}=\mathrm{pt} 21.6 .556 \& \mathrm{r}$ $=$ PART\&ty=HTML\#se21.6.556_1286.

FARAD (Food Animal Residue Avoidance Databank). 2020. ELDU and withdrawal time. Accessed Dec. 9, 2020. http://www.farad .org/eldu-and-withdrawal-time.html.

Gorden, P. J., M. D. Kleinhenz, R. Warner, P. K. Sidhu, and J. F. Coetzee. 2019. Short communication: Determination of the milk pharmacokinetics and depletion of milk residues of flunixin following transdermal administration to lactating Holstein cows. J. Dairy Sci. 102:11465-11469. https://doi.org/10.3168/jds.2019 -16639 .

Graves, M. T., L. Schneider, S. Cox, M. Caldwell, P. Krawczel, A. Lee, and A. Lear. 2020. Evaluation of the pharmacokinetics and efficacy of transdermal flunixin for pain mitigation following castration in goats. Transl. Anim. Sci. 4:txaa198. https://doi.org/10 $.1093 /$ tas/txaa198.

Kissell, L. W., G. W. Smith, T. L. Leavens, R. E. Baynes, H. Wu, and J. E. Riviere. 2012. Plasma pharmacokinetics and milk residues of flunixin and 5-hydroxyflunixin following different routes of administration in dairy cattle. J. Dairy Sci. 95:7151-7157. https://doi .org/10.3168/jds.2012-5754.

Kleinhenz, M. D., P. J. Gorden, J. S. Smith, J. A. Schleining, K. E. Kleinhenz, J. R. Juarez, D. Rea, and J. F. Coetzee. 2019. Effects of transdermal flunixin meglumine on experimentally induced lameness in adult dairy cattle. J. Dairy Sci. 102:6418-6430. https://doi .org/10.3168/jds.2018-15091.

Kleinhenz, M. D., N. K. Van Engen, P. J. Gorden, B. KuKanich, S. M. Rajweski, and J. F. Coetzee. 2016. The pharmacokinetics of transdermal flunixin meglumine in Holstein calves. J. Vet. Pharmacol. Therap. 39:612-615. https://doi.org/10.1111/jvp.12314.

Kleinhenz, M. D., N. K. van Engen, P. J. Gorden, J. Ji, P. Walsh, and J. F. Coetzee. 2017. Effects of transdermal flunixin meglumine on pain biomarkers at dehorning in calves. J. Anim. Sci. 95:19932000. https://doi.org/10.2527/jas2016.1138.

Kleinhenz, M. D., N. K. van Engen, J. S. Smith, P. J. Gorden, J. Ji, C. Wang, S. C. B. Perkins, and J. F. Coetzee. 2018. The impact of transdermal flunixin meglumine on biomarkers of pain in calves when administered at the time of surgical castration without local anesthesia. Livest. Sci. 212:1-6. https://doi.org/10.1016/j.livsci .2018.03.016.

Königsson, K., K. Törneke, I. V. Engeland, K. Odensvik, and H. Kindahl. 2003. Pharmacokinetics and pharmacodynamic effects of flunixin after intravenous, intramuscular and oral administration to dairy goats. Acta Vet. Scand. 44:153-159. https://doi.org/10 .1186/1751-0147-44-153.

Lees, P. 2017. Analgesic, anti-inflammatory, antipyretic drugs. Pages 467-500 in Veterinary Pharmacology and Therapeutics. J. E. Riviere and M. G. Papich. Wiley-Blackwell.

Monti, D. J. 2000. AMDUCA regulates small and large animal practice. J. Am. Vet. Med. Assoc. 216:1889.

Nixon, E., G. W. Almond, R. E. Baynes, and K. M. Messenger. 2020. Comparative plasma and interstitial fluid pharmacokinetics of meloxicam, flunixin, and ketoprofen in neonatal piglets. Front. Vet. Sci. 7:82. https://doi.org/10.3389/fvets.2020.00082.

NRC (National Research Council). 1981. Nutrient Requirements of Goats: Angora, Dairy, and Meat Goats in Temperate and Tropical Countries Committee on Animal Nutrition, Number 15. Pages 1-100 in Nutrient Requirements of Domestic Animals. National Academy Press.

Plummer, P. J., and J. A. Schleining. 2013. Assessment and management of pain in small ruminants and camelids. Vet. Clin. North Am. Food Anim. Pract. 29:185-208. https://doi.org/10.1016/j .cvfa.2012.11.004.

Reppert, E. J., M. D. Kleinhenz, S.R. Montgomery, H.N. Bornheim, G. Magnin, P.K. Sidhu, Y. Zhang, H. Joo, and J. F. Coetzee., 2019. Pharmacokinetics and pharmacodynamics of intravenous and transdermal flunixin meglumine in meat goats. J. Vet. Pharmacol. Therap. 42:309-317. https://doi.org/10.1111/jvp.12756.

Smith, J. S., T. L. Marmulak, J. A. Angelos, Z. Lin, J. D. Rowe, J. L. Carlson, W. L. Shelver, E. A. Lee, and L. A. Tell. 2020. Pharmacokinetic parameters and estimated milk withdrawal intervals for domestic goats (Capra Aegagrus Hircus) after administration of single and multiple intravenous and subcutaneous doses of flunixin meglumine. Front. Vet. Sci. 7:213. https://doi.org/10.3389/fvets .2020 .00213 .

Thiry, J., R. Fournier, O. Roy, and M. Catala. 2017. Evaluation of flunixin meglumine pour-on administration on prostaglandin $\mathrm{E}_{2}$ 
concentration in inflammatory exudate after induction of inflammation in cattle. Res. Vet. Sci. 114:294-296. https://doi.org/10 $.1016 /$ j.rvsc.2017.04.010

Toutain, P. L., A. Ferran, and A. Bousquet-Mélou. 2010. Species differences in pharmacokinetics and pharmacodynamics. Pages 19-48 in Comparative and Veterinary Pharmacology. F. Cunningham, J. Elliott, P. Lees, eds. Springer. https://doi.org/10.1007/978-3-642 $-10324-7 \_2$.

Toutain, P. L., S. Modric, A. Bousquet-Mélou, J. M. Sallovitz, and C. Lanusse. 2012. Should licking behavior be considered in the bioavailability evaluation of transdermal products? J. Vet. Pharmacol. Ther. 35(Suppl. 1):39-43. https://doi.org/10.1111/j.1365 $-2885.2012 .01380 . x$

US FDA (Food and Drug Administration). 2017. Freedom of Information Summary, Original New Animal Drug Application, NADA 141-450, Banamine Transdermal, Flunixin Transdermal Solution. Accessed Mar. 13, 2021. https://animaldrugsatfda.fda.gov/ adafda/app/search/public/document/downloadFoi/1944.

US FDA (Food and Drug Administration). 2020. Drug residues. Accessed Dec. 9, 2020. https://www.fda.gov/animal-veterinary/ compliance-enforcement/drug-residues.
US FDA (Food and Drug Administration). 2006. General Principles for Evaluating the Human Food Safety of New Animal Drugs Used in Food-Producing Animals Guidance for Industry. Docket number 2005D-0219. FDA.

US FDA (Food and Drug Administration). 2018. General Principles for Evaluating the Human Food Safety of New Animal Drugs Used in Food-Producing Animals Guidance for Industry. Docket number FDA-2005-D-0155. FDA.

\section{ORCIDS}

Emily E. Wiloch ำ https://orcid.org/0000-0003-4677-395X Emma Nixon ๑ https://orcid.org/0000-0002-6570-4928

Geof W. Smith ৫ https://orcid.org/0000-0001-5700-8810

Ronald E. Baynes ๑ https://orcid.org/0000-0002-7920-9338 